\title{
List of Reviewers for this Focused Issue
}

Journal of International Business Studies (2007) 38, 121 I. doi: I0. 1057/palgrave.jibs.8400323

The guest editors wish to acknowledge and thank members of the Editorial Review Board and the scholars listed below who have contributed their time to review manuscripts for this 'Internationalization Positions, Paths and Processes' Focused Issue.

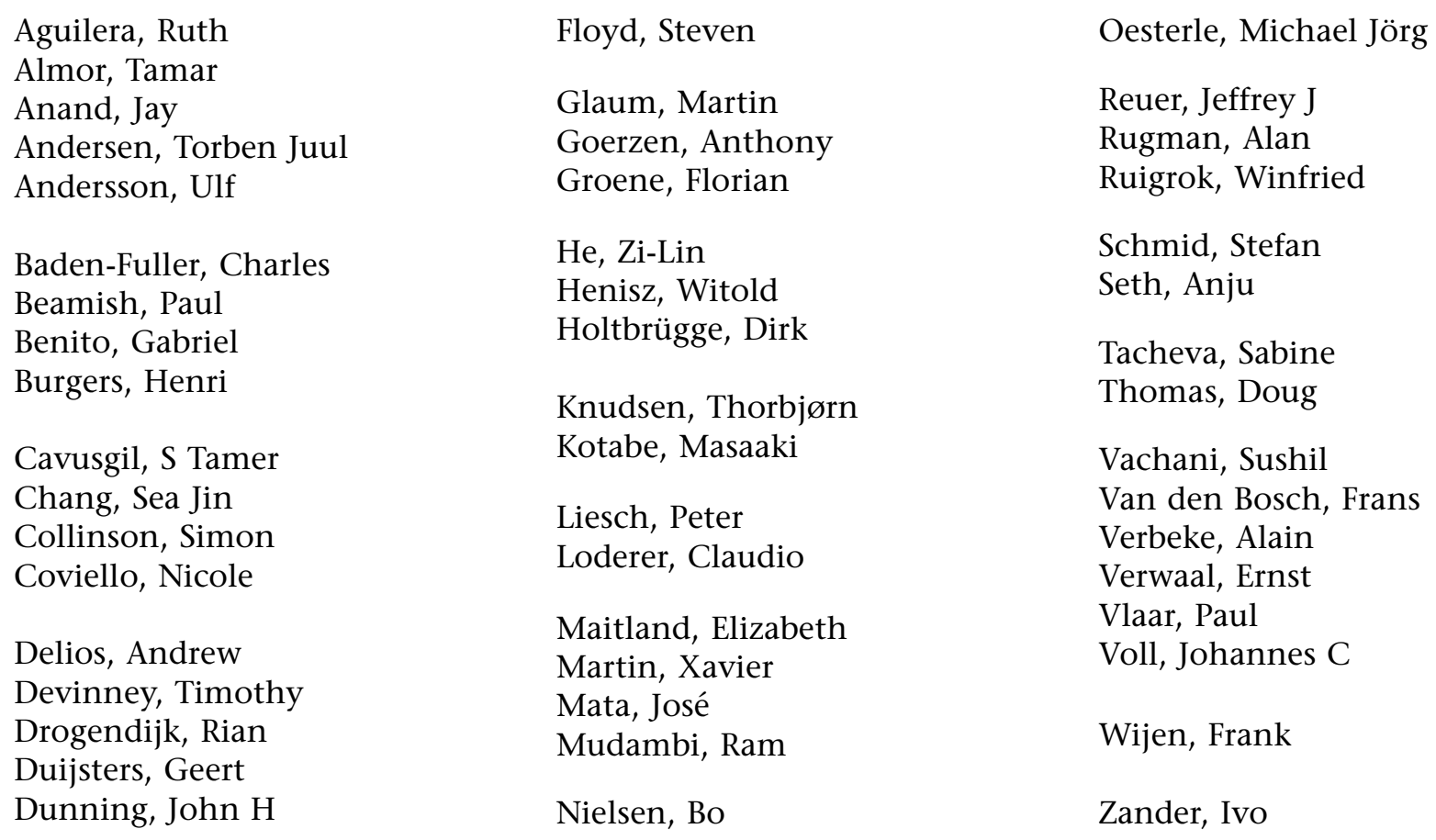

